\title{
A Study of Contact Interface for an Anti-Rotation Rivet Using Ultrasonic Detection
}

\author{
Chuang Wen Yao and Hsueh Chih Cheng \\ Department of Mold and Die Engineering, National Kaohsiung University of Applied Sciences No. 415, Chien- \\ Kung Rd. Kaohsiung city 80778, Taiwan.
}

\begin{abstract}
(Received 16 December 2016; accepted 19 February 2018)
This work measures the contact area between an anti-rotation rivet and an aluminum plate under different riveting loads based on the regional scanning of ultrasound. The contact image is a novel disclosure for the anti-rotation rivet contact. The $2 \mathrm{D}$ maps show an apparent change not only in area sizes but also in contact shapes under various normal forces applied. The 3D contact images also provide useful information to show the intensity of contact.

The contact area between the anti-rotation rivet and the aluminum is calculated using an image analysis software package. The range of contact areas varies from $6.3 \mathrm{~mm}^{2}$ to $57.2 \mathrm{~mm}^{2}$, depending on the applied forces and the definition of the contrast ratio. Furthermore, a calibration of data fitting is performed to provide a useful polynomial equation for contact area estimation. In addition, maps of both a reflection coefficient and a pressure contour distribution are presented. The range of peak contact pressure varies from 7.1 MPa to 11.2 MPa.
\end{abstract}

\section{NOMENCLATURE}

\section{A contact area}

$R \quad$ reflection coefficient

$z_{i} \quad$ acoustic impedance

$\omega \quad$ angular frequency

$K \quad$ stiffness of interface

$p \quad$ contact pressure

$u \quad$ mean surface roughness

$U P R \quad$ ultrasonic pulse receiver

FFT Fast Fourier Transform

$P I A \quad$ Power Image Analysis

$c_{i} \quad$ polynomial parameters of equation

$q \quad$ arbitrary constant

$S_{j} \quad$ the $j$ th signal amplitude.

$l_{w} \quad$ focal length in water

$c_{w} \quad$ speed of sound in water

$f \quad$ ultrasonic frequency

$D \quad$ transducer element diameter

\section{INTRODUCTION}

Prior to the wide application of welding and bolt technology, many metal structure buildings were fixed by riveting, such as the Eiffel Tower and the Sydney Harbor Bridge. Previously, some car chassis were fixed by riveting. In modern car manufacturing, self piercing rivets (SPR) are widely used for aluminum components assembly due to their remarkable advantages. ${ }^{1}$ It also becomes the field in which many researchers are interested, ${ }^{2-4}$ including the possibility of joining two aluminum plates by using self piercing rivets by Hoang et al. ${ }^{5}$ and Abe et al. ${ }^{6}$ It is well known that the fracture behavior occurs significantly depending on the stress state. Numerous studies on the stress concentration of two-dimensional plates with circular holes subjected to several loading types were summarized in the literature. ${ }^{7}$ Eddy current detection is the most common method used to examine riveting in conventional structure. ${ }^{8}$ He et al. ${ }^{9}$ used a pulsed eddy current technique to exam- ine the defects in multi-layer structures of aircrafts. Diraison et al. ${ }^{10}$ and Liu et al. ${ }^{11}$ used an eddy current method to investigate the aircraft lap-joint riveting. However, the conventional rivets were not the subject in this study. Instead, an anti-rotation rivet with special contact surface which has the ability of torsional resistance was the focus of this work.

Conventional rivets are fasteners that are used to affix two work pieces mechanically and permanently. Rivets usually consist of a head (or flange) and a shaft that is inserted into a hole of the affixed parts. They can support tension forces parallel to the shaft and shear forces perpendicular to the shaft depending on the material limits of the rivet and the structures being affixed. Yan et al. ${ }^{12}$ performed experimental investigation for the shear strength of self-piercing rivet connections and suggested a design method for thin-walled steel structures. Recently there were a few patented rivets proposed to provide torsion resistance, which were used for special applications. ${ }^{13}$ In this application, the rivets were designed to have a corrugated surface, which can comprise ridges having height. The ridges were comprised of inclined ramps sloping from the contacting side to the height of the ridge. It was not only to support high shear force and tension force, but also to prevent rotation for the purposed rivets. The characteristic for these rivets was to provide ability of anti-rotation.

There was almost no research concerning these special purposed rivets. In this work, the objective was to study the contact interface for the anti-rotation rivet, the measurement of the contact area and the estimation of contact pressure. While studying the contact stress, there was no doubt that contact area size plays an important role in doing relative studies.

In contrast with the usual single contact between two common objects, an anti-rotation rivet usually has several contact points between the rivet and the workpiece. It was difficult to apply theoretical models to predict the multiple contact regions between two objects. An efficient and convenient method to investigate the contact interface and to measure the area size was to use both ultrasonic scanning and signal processing. A sin- 
gle ultrasonic transducer performed a regional scanning and a point measurement of reflection. A 2D map of the reflection was obtained when the transducer moved back and forth across the interface area. The detailed processes can be found in some references, ${ }^{14-16}$ both analytically and empirically.

\section{BACKGROUND}

\subsection{Ultrasonic Theory}

When an ultrasonic wave is incident on a micro-scale real engineering surface consisting of micro-asperities, the signal was partially transmitted through the asperity contacts and partially reflected by the air gaps. A reflection coefficient, $R$, was defined for an interface as a ratio of the amplitude of the reflected pulse to the amplitude of the incident pulse, depending on the acoustic impedance of the two contacting materials. Acoustic impedance was a material property defined as the product of density and wave speed in a given material. In theory, the reflection coefficient, $R$, was determined by equation: ${ }^{17}$

$$
R=\frac{z_{1}-z_{2}}{z_{1}+z_{2}}
$$

where $z$ was the acoustic impedance of the material and the subscripts refer to the two sides of the interface.

For example, the impedance of air, water and aluminum were $0.0004,1.51$ and $17.03 \mathrm{~kg} \mathrm{~m}^{-2} \mu \mathrm{sec}^{-1}$, respectively, so when a pulse struck an aluminum/air interface $\left(z_{1}>>z_{2}\right)$ it was almost totally reflected and the reflection coefficient approached $100 \%$. If the wave struck an aluminum/aluminum interface and there was perfect contact, it was fully transmitted $\left(z_{1}=z_{2}\right)$ and $R$ approached zero.

The surfaces between an anti-rotation rivet and an aluminum plate were rough and, in micro view, the rough surface was composed of individual asperity junctions and air gaps. An ultrasonic wave was transmitted through a rough surface interface where there was asperity-to-asperity contact and reflected where there were small air gaps. So, it was possible to perform a scan of the reflected ultrasound across an interface. The detail of the relationship between the reflection coefficient and the rough surface contact conditions can be found in references. ${ }^{18-21}$

\subsection{Spring Model of Contact Surface}

For an imperfect interface, a contact spring mode ${ }^{22}$ can be used to study ultrasonic reflection coefficient to the stiffness of the interface. The interface was represented by a series of flexible springs. The reflection coefficient depended on the stiffness of the interface spring, $K$, according to:

$$
R=\frac{z_{1}-z_{2}+i \omega\left(z_{1} z_{2} / K\right)}{z_{1}+z_{2}+i \omega\left(z_{1} z_{2} / K\right)}
$$

where $\omega$ was the angular frequency $(2 \pi f)$ of the ultrasound wave and $z$ was the acoustic impedance.

The stiffness $K$ of an interface was a measure of its ease of closure and was defined as the change in nominal contact pressure, $p$, required to cause unit approach of the mean lines of the surfaces. ${ }^{23}$ Thus:

$$
K=-\frac{d p}{d u}
$$

where $K$ was stiffness per unit area, $d p$ was the change in pressure and $u$ was the separation of the mean lines of roughness of the two surfaces. The concept was used to deduce the contact pressure from the reflected coefficient of ultrasonic pulse.

The stiffness, and hence the reflection coefficient from Eq. (2), varied with contact pressure. Measurement of the reflection coefficient can then give information about the degree of contact at an interface and the distribution of the contact pressure.

\subsection{Importance of Riveting and Effect of Surface Roughness}

Some light weight and high strength designs which apply directly riveting in order to join the work pieces, such as pressure vessels and civil aircraft structure. They were composed of a multi-piece aluminum alloy plate combination which is currently assembled by rivets. Riveting was suitable for most joint cases because it will not cause the metal deformation and change in metallic properties like the welding method. However, there are some reports that a civil aircraft shell skin presented tiny gaps because of poor riveting construction or after a period of time due to material fatigue. The outcome lead to aircraft damage from urgent landing to serious crashes. Take the contact examination between aircraft skin and rivets as an example, the existence of structural damage or internal cracks cannot easily be recognized by looking with visual inspection. Therefore, ultrasonic detection was usually used to determine the safety of riveting for the aircrafts.

Rivets are mechanical fasteners that are used to hold two metal plates together permanently. Although welding can do the same work as well, riveting still has its dominant advantage. The significant difference between welding and riveting is the effect of surface roughness between contact interfaces. In riveting, a hole needs to be bored through the plates before the rivet is inserted. Then the two ends of the rivet will be made shapes like a mushroom cap on either side of the plates in order to affix the metal plates tightly. Surface roughness still exists in even highly polished metal plates and significantly affects real contact situations. Because of this roughness, only a part of the surface is in contact. The contact area depends on the geometry of both the anti-rotation rivet and the surface roughness. In this study, an ultrasonic pulse was used to identify the contact interface for various applied forces. For a real engineering problem, the real contact shapes and area size can only be determined by doing experiments.

\subsection{Transducer Focusing}

A parallel beam of ultrasound emitted from a transducer at the diameter of the piezoelectric plate was sometimes influenced by wave scattering. In order to increase the sensitivity of the ultrasonic transducer and prevent the effect of scattering, focusing reduced the diameter of the emitted sound wave. The plate at the front of the transducer was ground to form a concave lens; this provided the initial convergence of the signal. Using the concave lens described, the ultrasonic signal was focused onto an interface to facilitate its investigation. It was necessary to either adjust the transducer's position or move the 


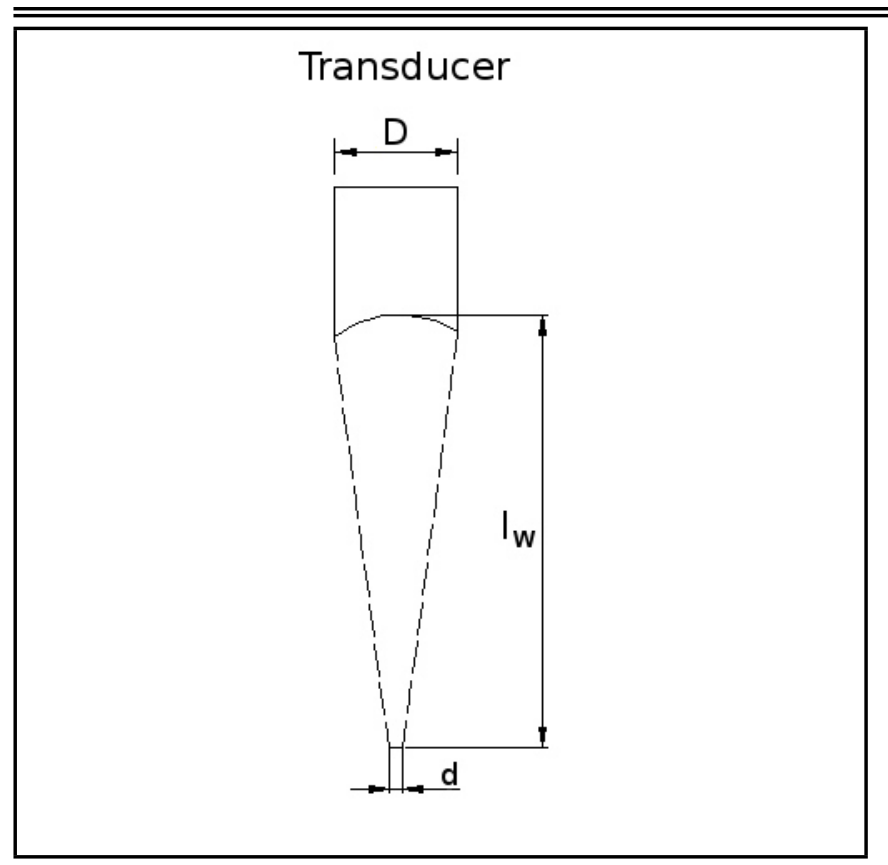

Figure 1. Transducer focusing to increase scanning resolution.

position of the target object in order to make the focused point of signals be located on the interface of interest.

The ultrasound focused down to a finite spot, shown in Fig. 1. The spot diameter, $d$, was the resolution of the ultrasonic technique, and was expressed as follows: ${ }^{24}$

$$
d=\frac{1.028 l_{w} c_{w}}{f D}
$$

where $l_{w}$ was the focal length in water (1 inch), $c_{w}$ was the speed of sound in water $(1481 \mathrm{~m} / \mathrm{sec}), f$ was the ultrasonic frequency $(10 \mathrm{MHz})$, and $D$ was the transducer element diameter $(0.5 \mathrm{inch})$. Therefore, in this case, the spot diameter, $d$, was $0.3 \mathrm{~mm}$. It was essential when choosing a transducer for a given application that the spot diameter was minimised, as this maximises the resolution of the ultrasonic technique.

\section{APPARATUS AND EXPERIMENTAL PROCEDURE}

\subsection{Test Specimens and Loading Apparatus}

The anti-rotation rivet for this test was made of aluminum and had a head that measured $18 \mathrm{~mm}$ in diameter. Figure 2 shows a photograph of the anti-rotation rivet. It can be easily visualized that there are anti-rotation design curves under the rivet head. In order to make the contact interface easier to set up and to simplify the measuring process, the stem part of the rivet was cut off so only the rivet head contacted the aluminum plate. Figure 3 shows the schematic of the rivet/workpiece contact and the loading frame. The anti-rotation rivet and aluminum plate were put together and then were placed inside a frame. A hydraulic cylinder was used to apply normal load to the contact specimens. This frame was designed and produced explicitly for various experiments of contact measurement using ultrasonic scanning.

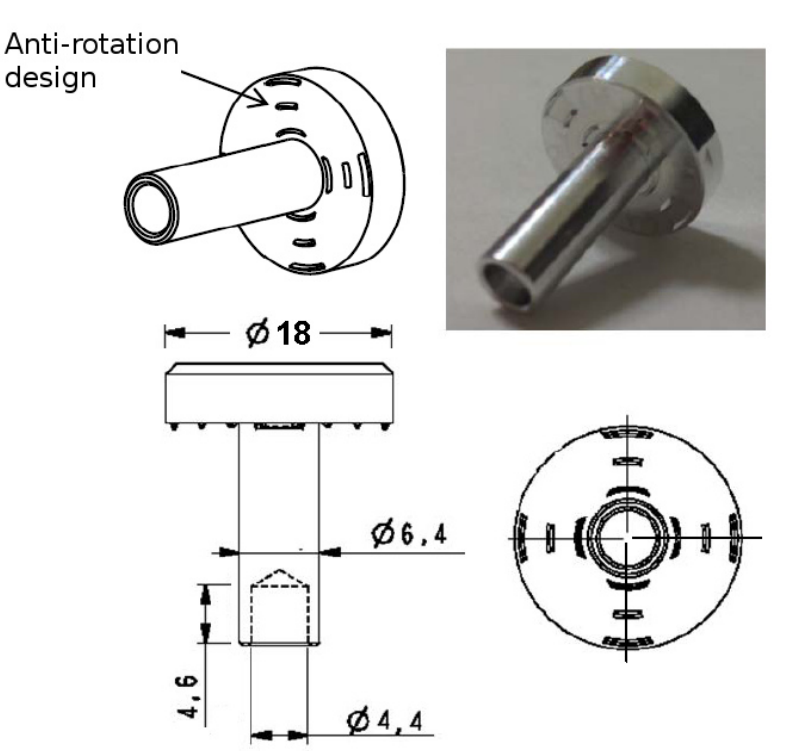

Figure 2. A photograph of the anti-rotation rivet and the detail design.

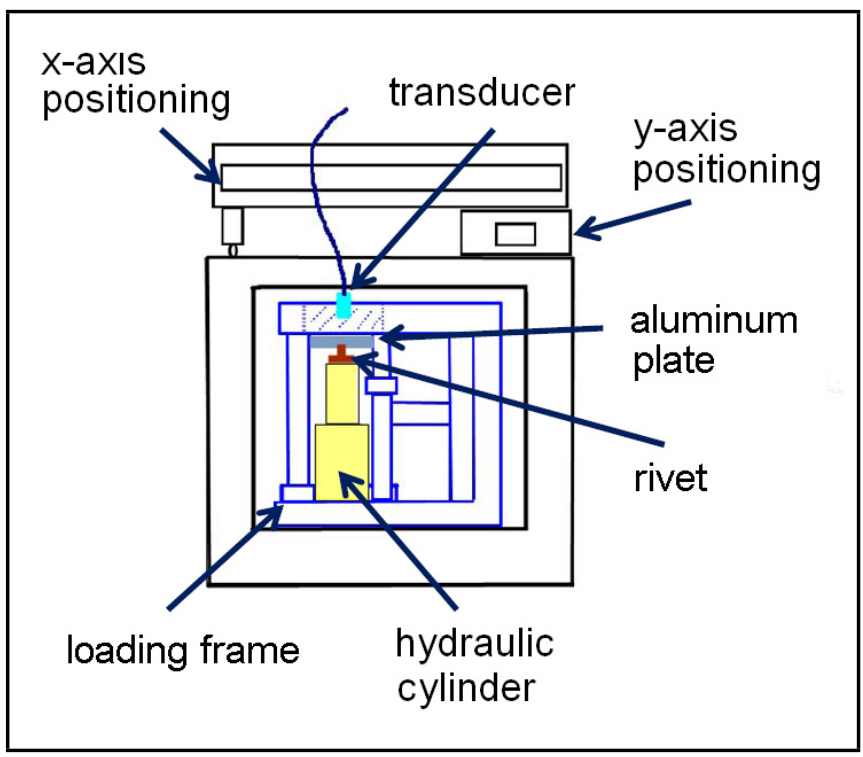

Figure 3. Schematic of rivet/workpiece contact and the loading frame.

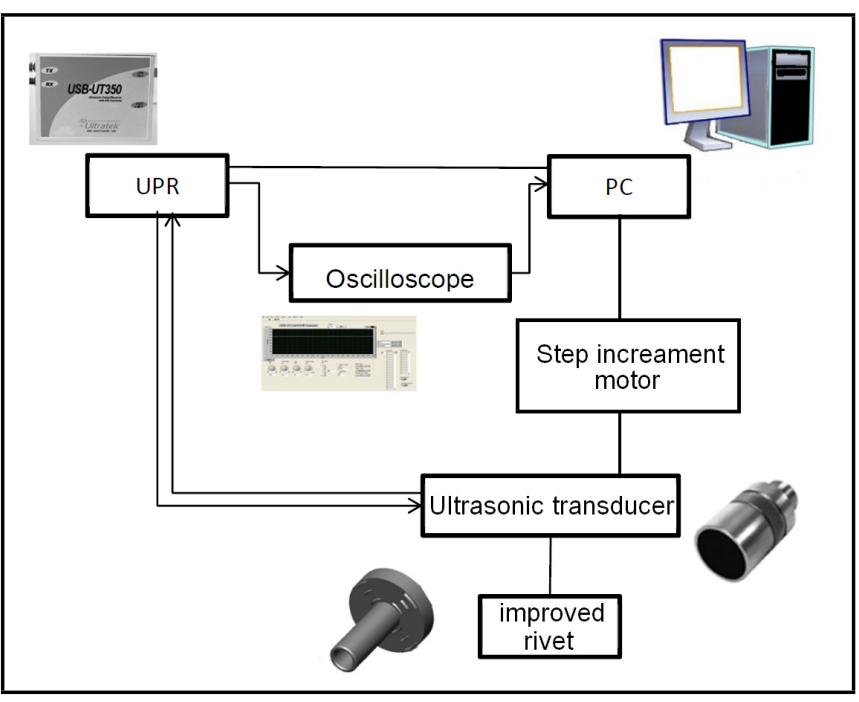

Figure 4. A schematic of the ultrasonic instrumentation. 


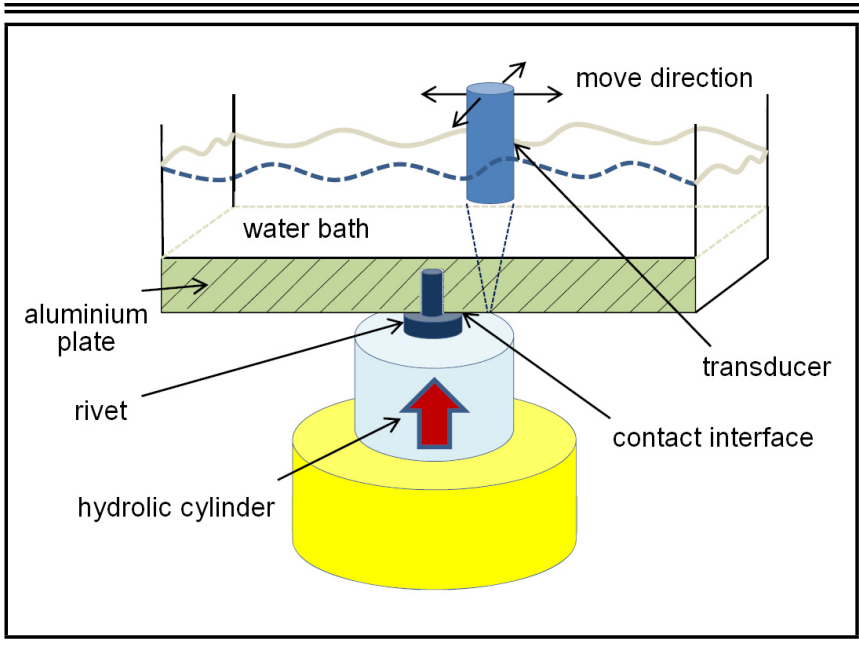

Figure 5. Schematic layout of contact interface and the scanning procedure.

\subsection{Ultrasonic Scanning Apparatus}

A scanning device was designed to conduct the measurement. This device consisted of an ultrasonic pulse receiver (UPR), an oscilloscope, a data processing computer and a 10 $\mathrm{MHz}$ spherical focusing transducer. The measuring procedure was automatic. The transducer, excited by the UPR, was immersed in a water bath and was positioned above the contact specimen, in order to focus the pulses onto the contact interface, and then scanned over a given area. Once the incident ultrasonic signal was reflected from the contact interface at prescribed intervals, the readings were then taken for further processing. The dimensions and resolution of the scan were determined by the specimen geometry and the moving pitch of the transducer. Figure 4 shows a schematic of the ultrasonic instrumentation.

\subsection{Scanning Procedure and Signal Processing}

Figure 5 shows both the schematic of scanning procedure and the movement of the transducer. This was a 2D automatic scanning process. The ultrasonic transducer was mounted in a water bath and moved back and forth controlled by stepper motors linked to the PC. Then the transducer was moved up and down, to focus the emitted pulses onto the contact interface and to determine the maximum signal amplitude. Once it had been focused on the interface, the transducer was scanned over the contact region along the $x$ and $y$ directions, in increments of $d x$ and $d y$, until the entire desired region had been inspected.

A software interface, which was written in Labview, performed a Fast Fourier Transform (FFT) of the signal and performed the follow-up processing tasks, to produce useful data. Due to partial transmission of the signal at the interface and attenuation in the material bulk, the reflected signal from the interface had a lower value than the emitted pulses. The relationships between reflected and emitted signals in the frequency domain were calculated. From the experimental data recorded by the computer, the reflected signal readings were then processed, and the contact patches were generated, using MATLAB program.

\section{RESULTS}

\subsection{Scanning Amplitude Map}

Figure 6 shows the scanning amplitude map of 2D and 3D for the contact between an anti-rotation rivet and an aluminum plate under normal forces of $2.0,2.5,3.0,3.5$ and $4.0 \mathrm{kN}$ applied. In these pictures, the contact regions between the rivet/plate interfaces are clearly identified. The contact shapes are revealed for the first time under the ultrasonic wave scanning. It shows that the contact images are not completely the same and the shapes can only be obtained by experiments instead of previous prediction. The $2 \mathrm{D}$ maps clearly indicate the variation of the contact shapes which become greater and greater when the applied normal forces increase from $2.0 \mathrm{kN}$ to $4.0 \mathrm{kN}$. The 3D maps show the variation of the contact shapes provided in another point of view to indicate the differences. In theory, the four parts (top, bottom, right and left sides) of antirotation design should appear in shapes simultaneously and be approximately similar in size. However, probably because of production tolerance for the anti-rotation rivet, the pictures show that the four groups of contact patches are differently sized and shaped.

\subsection{Image Processing and Area Estimation}

The next task was to estimate the size of contact area, which was accomplished by using a commercial software package called Power Image Analysis (PIA). In the process of applying a force, the real contact region gradually increased from slight contact to full contact, which made the reflected signals different. Therefore, the collected amplitude data can reveal the formation process of the image shape, depending on whether the contact was light or heavy. Prior to the area calculation, the contrast ratio had to be defined in order to indicate the degree of contact according to different signal amplitude. Figure 7 shows the concept and the image variations for increasing contrast ratios from $10 \%$ to $100 \%$.

Upon obtaining the image shapes for contrast ratios from $10 \%$ to $100 \%$, in $10 \%$ increments, the following task was to estimate the image area by using the function of image processing software package. The first step was to define the reference length on the computer display. Because the original scanned region was set to be a square of $18 \mathrm{~mm} \times 18 \mathrm{~mm}$, the width in $x$-direction of each scanned image was defined as 18 $\mathrm{mm}$, on the computer screen. The second step was to select the contact images by using a block selection function. Then the areas of the selected contact patches were obtained from the digital format shown on the screen. The reference ${ }^{25}$ shows the detail procedures. Using these procedures, the contact areas were calculated and shown in Tab. 1. Figure 8 shows the variation matrix of contact shapes under various loads and contrast ratios.

\subsection{Area Prediction by Multivariable Curve Fitting Technique}

Curve fitting is a technique that is used to capture the trend in the experimental data by assigning a single function across the entire range. Table 1 contains the experimental data of area measurement, which can be processed by data curve fitting in 


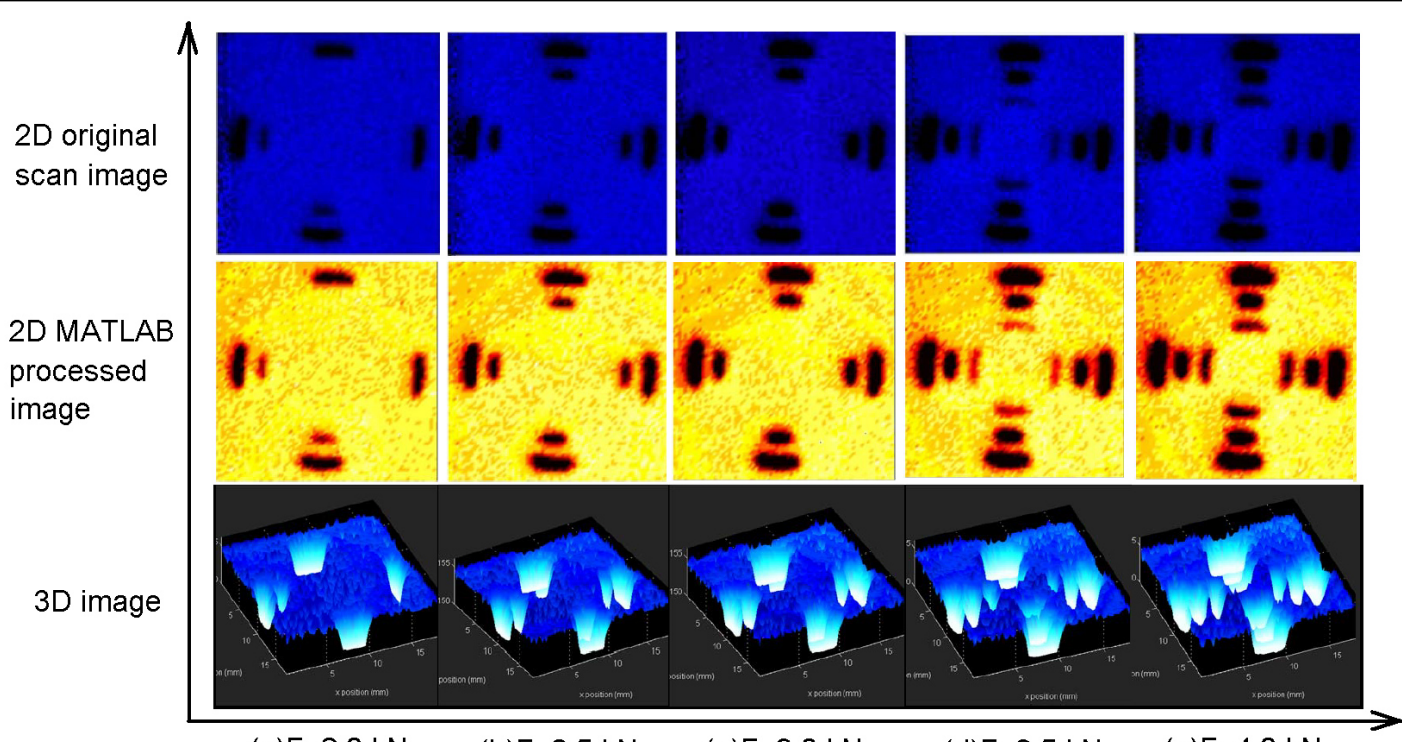

(a) $\mathrm{F}=2.0 \mathrm{kN}$

(b) $\mathrm{F}=2.5 \mathrm{kN}$

(c) $\mathrm{F}=3.0 \mathrm{kN}$

(d) $F=3.5 \mathrm{kN}$

(e) $\mathrm{F}=4.0 \mathrm{kN}$

Figure 6. $2 \mathrm{D}$ and $3 \mathrm{D}$ contact pictures between an anti-rotation rivet and an aluminum plate under normal load, $\mathrm{F}, \mathrm{F}=2.0 \mathrm{kN}$, (b) $\mathrm{F}=2.5 \mathrm{kN}$, (c) $\mathrm{F}=3.0 \mathrm{kN},(\mathrm{d})$ $\mathrm{F}=3.5 \mathrm{kN}$ and (e) $\mathrm{F}=4.0 \mathrm{kN}$.

Table 1. Contact area for the rivet/plate interface, under different contrast ratios. Unit: $\mathrm{mm}^{2}$.

\begin{tabular}{|c|c|c|c|c|c|c|c|c|c|c|}
\hline \multirow{2}{*}{ Normal loads } & \multicolumn{10}{|c|}{ Contrast } \\
\hline & $10 \%$ & $20 \%$ & $30 \%$ & $40 \%$ & $50 \%$ & $60 \%$ & $70 \%$ & $80 \%$ & $90 \%$ & $100 \%$ \\
\hline $2.0 \mathrm{kN}$ & 6.32 & 7.87 & 9.33 & 10.69 & 12.07 & 13.55 & 15.05 & 16.28 & 17.61 & 18.77 \\
\hline $2.5 \mathrm{kN}$ & 9.97 & 12.29 & 14.62 & 16.82 & 18.76 & 21.51 & 22.64 & 24.44 & 26.14 & 27.87 \\
\hline $3.0 \mathrm{kN}$ & 14.94 & 18.80 & 19.79 & 22.14 & 24.38 & 26.47 & 28.76 & 31.01 & 33.05 & 35.67 \\
\hline $3.5 \mathrm{kN}$ & 17.44 & 20.79 & 23.71 & 26.32 & 28.86 & 33.04 & 34.68 & 39.03 & 41.94 & 44.65 \\
\hline $4.0 \mathrm{kN}$ & 21.92 & 27.34 & 30.76 & 34.45 & 38.95 & 42.78 & 45.74 & 50.85 & 54.20 & 57.20 \\
\hline
\end{tabular}

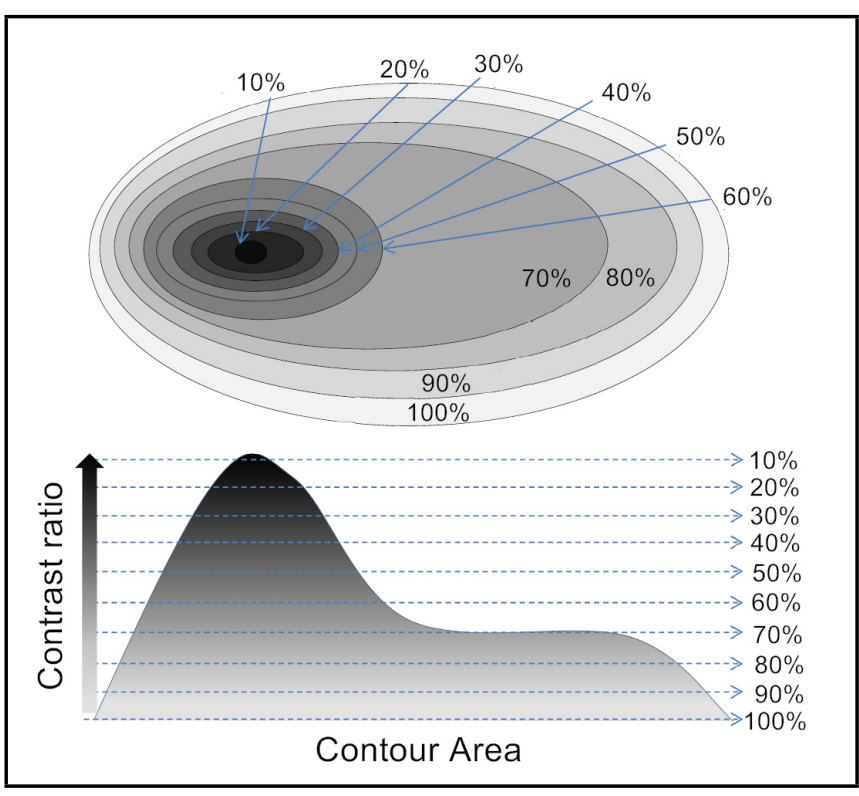

Figure 7. Concept of the contrast ratio and variation in image size with increasing contrast ratio.

order to find an equation for area prediction. In the experimental process, the two independent variables for the change of contact area are normal loadings and contrast ratio. Let the contrast ratio as $x$ input and the normal load as $y$ input. The contact area was denoted as the output, $A$, which was a $2 \mathrm{D}$ matrix. The expression related $A$ to a function of $x$ and $y$ :

$$
A=f(x, y) \text {. }
$$

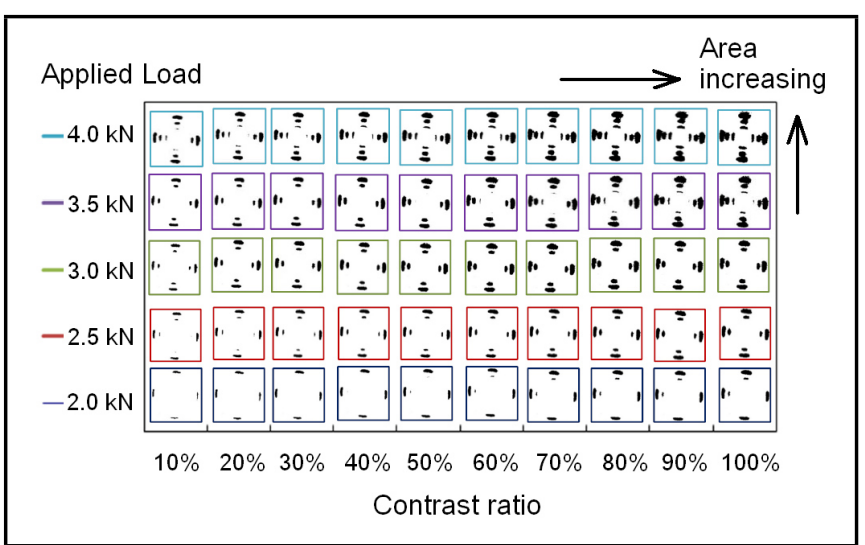

Figure 8. The variation matrix of contact shapes under various loads and contrast ratios.

Table 2. The parameters for the Eq. (6).

\begin{tabular}{|c|cccccc|}
\hline Parameters & $C_{1}$ & $C_{2}$ & $C_{3}$ & $C_{4}$ & $C_{5}$ & $C_{6}$ \\
\hline Values & 2.955 & -9.032 & -1.404 & -1.957 & 12.07 & 1.358 \\
\hline
\end{tabular}

By using MATLAB function, $\operatorname{cftool}(\mathrm{x}, \mathrm{y}, \mathrm{A})$, and selecting the Polynomial Model, the contact area, $A$, was expressed as follows:

$$
A=c_{1}+c_{2} x+c_{3} y+c_{4} x^{2}+c_{5} x y+c_{6} y^{2}
$$

where $c_{1}, c_{2}, c_{3}, c_{4}, c_{5}$ and $c_{6}$ were the polynomial parameters. Table 2 shows the values of these parameters by using MATLAB program.

According to the Eq. (6), the contact area for any normal load ranged from $2.0 \mathrm{kN}$ to $4.0 \mathrm{kN}$ and the contrast ratio, which 


\begin{tabular}{|c|c|c|c|c|c|c|c|c|c|c|}
\hline \multirow{2}{*}{ Normal loads } & \multicolumn{10}{|c|}{ Contrast } \\
\hline & $10 \%$ & $20 \%$ & $30 \%$ & $40 \%$ & $50 \%$ & $60 \%$ & $70 \%$ & $80 \%$ & $90 \%$ & $100 \%$ \\
\hline $2.0 \mathrm{kN}$ & $\begin{array}{c}7.07 \\
(11.87 \%)\end{array}$ & $\begin{array}{c}8.52 \\
(8.29 \%)\end{array}$ & $\begin{array}{c}9.94 \\
(6.54 \%)\end{array}$ & $\begin{array}{c}11.31 \\
(5.80 \%)\end{array}$ & $\begin{array}{c}12.64 \\
(4.72 \%)\end{array}$ & $\begin{array}{c}13.94 \\
(2.88 \%)\end{array}$ & $\begin{array}{c}15.19 \\
(0.93 \%)\end{array}$ & $\begin{array}{c}16.41 \\
(0.80 \%)\end{array}$ & $\begin{array}{c}17.59 \\
(-0.11 \%)\end{array}$ & $\begin{array}{c}18.73 \\
(-0.21 \%)\end{array}$ \\
\hline $2.5 \mathrm{kN}$ & $\begin{array}{c}10.03 \\
(0.60 \%)\end{array}$ & $\begin{array}{c}12.08 \\
(-1.71 \%)\end{array}$ & $\begin{array}{c}14.10 \\
(-3.56 \%)\end{array}$ & $\begin{array}{c}16.08 \\
(-4.40 \%)\end{array}$ & $\begin{array}{c}18.01 \\
(-4.00 \%)\end{array}$ & $\begin{array}{c}19.91 \\
(-7.44 \%)\end{array}$ & $\begin{array}{c}21.77 \\
(-3.84 \%)\end{array}$ & $\begin{array}{c}23.59 \\
(-3.48 \%)\end{array}$ & $\begin{array}{c}25.38 \\
(-2.91 \%)\end{array}$ & $\begin{array}{c}27.12 \\
(-2.69 \%)\end{array}$ \\
\hline $3.0 \mathrm{kN}$ & $\begin{array}{c}13.66 \\
(-8.57 \%)\end{array}$ & $\begin{array}{c}16.32 \\
(-13.2 \%)\end{array}$ & $\begin{array}{c}18.94 \\
(-4.30 \%)\end{array}$ & $\begin{array}{c}21.52 \\
(-2.80 \%)\end{array}$ & $\begin{array}{c}24.06 \\
(-1.31 \%)\end{array}$ & $\begin{array}{c}26.57 \\
(0.38 \%)\end{array}$ & $\begin{array}{c}29.03 \\
(0.94 \%)\end{array}$ & $\begin{array}{c}31.45 \\
(1.42 \%)\end{array}$ & $\begin{array}{c}33.84 \\
(2.39 \%)\end{array}$ & $\begin{array}{c}36.18 \\
(1.43 \%)\end{array}$ \\
\hline $3.5 \mathrm{kN}$ & $\begin{array}{c}17.98 \\
(3.10 \%)\end{array}$ & $\begin{array}{c}21.24 \\
(2.16 \%)\end{array}$ & $\begin{array}{c}24.46 \\
(3.16 \%)\end{array}$ & $\begin{array}{c}27.65 \\
(5.05 \%)\end{array}$ & $\begin{array}{c}30.79 \\
(6.69 \%)\end{array}$ & $\begin{array}{c}33.90 \\
(2.60 \%)\end{array}$ & $\begin{array}{c}36.97 \\
(6.60 \%)\end{array}$ & $\begin{array}{c}39.99 \\
(2.46 \%)\end{array}$ & $\begin{array}{c}42.98 \\
(2.48 \%)\end{array}$ & $\begin{array}{c}45.93 \\
(2.87 \%)\end{array}$ \\
\hline $4.0 \mathrm{kN}$ & $\begin{array}{c}22.97 \\
(4.79 \%)\end{array}$ & $\begin{array}{c}26.84 \\
(-1.83 \%)\end{array}$ & $\begin{array}{c}30.67 \\
(-0.29 \%)\end{array}$ & $\begin{array}{c}34.45 \\
(0.01 \%)\end{array}$ & $\begin{array}{c}38.20 \\
(-1.93 \%)\end{array}$ & $\begin{array}{c}41.91 \\
(-2.03 \%)\end{array}$ & $\begin{array}{c}45.58 \\
(-0.35 \%)\end{array}$ & $\begin{array}{c}49.21 \\
(-3.23 \%)\end{array}$ & $\begin{array}{c}52.80 \\
(-2.58 \%)\end{array}$ & $\begin{array}{c}56.36 \\
(-1.47 \%)\end{array}$ \\
\hline
\end{tabular}

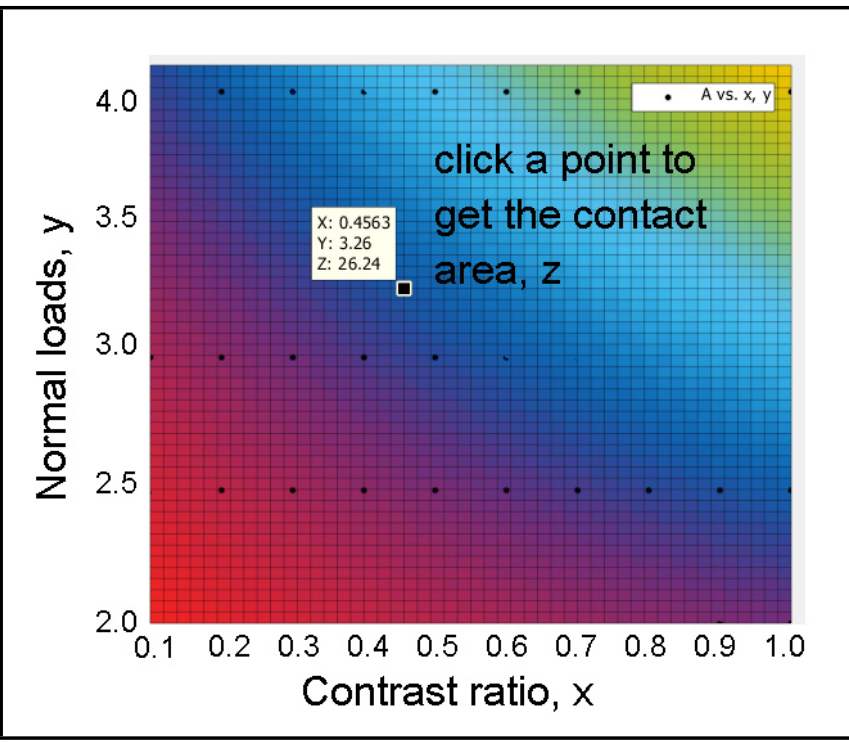

Figure 9. The operation screen of MATLAB to get the area at the selected conditions.

ranged from 0.1 to 1.0 , can be obtained. Figure 9 shows the operation screen to get the contact area for an example (loading $3.2 \mathrm{kN}$ and 0.45 contrast ratio). It is unavoidable to have numerical error between the experimental data and the curve fitting results. Table 2 shows the results by using fitting equation and the percentage error between measurement data and curve fitting methods. Figure 10 shows the result of curves.

\subsection{Reflection Coefficient and the Estimation of Contact Pressure}

The reflection coefficient, $R$, was defined as the proportion of the incident signal amplitude reflected from the interface. The previous recorded amplitude data was used to be further processed for the plotting of reflection coefficient. Figure 11 shows the maps of ultrasonic reflection coefficient for the rivet/plate contact. As to contact pressure, because the amplitude of the reflected signal was influenced by many factors, such as the number, size, distribution of the surface asperity and the contact intensity between two objects, there was no single relationship between contact pressure and signal amplitude. However, under the assumption of the quasi-static spring model between the interfaces, the pressure was assumed to be proportional to the signal amplitude. Thus, a calibration study can be proceeding to approximately estimate the contact pres-

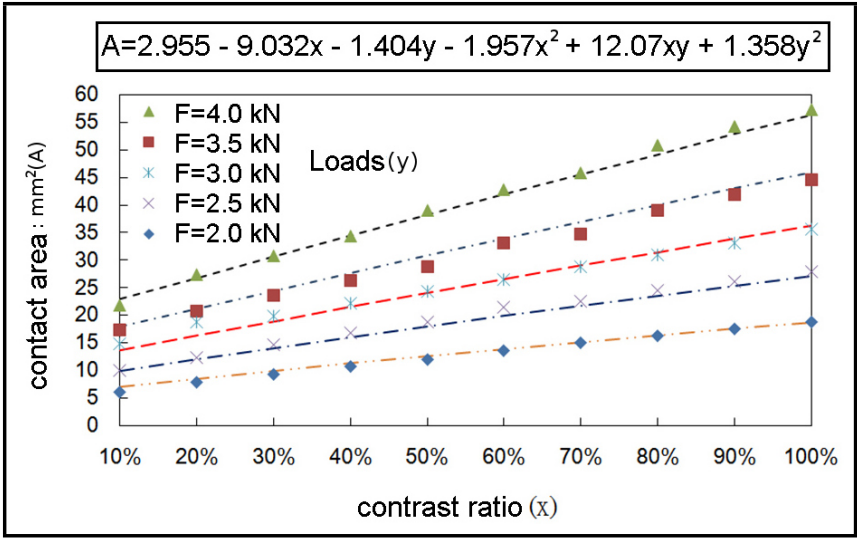

Figure 10. The projection on $x-A$ plane for the fitting function of contact area.

sure. Assume that pressure, $p_{j}$, was the pressure of the $j$ th contact region, then:

$$
p_{j}=q S_{j}
$$

where $q$ was an arbitrary constant and $S_{j}$ represented the $j$ th signal amplitude.

Ultrasonic pulses were emitted to detect an $18 \mathrm{~mm} \times 18 \mathrm{~mm}$ patch, obtaining a number of cells of the $76 \times 76$ signal matrix in which every reading represents the amplitude of ultrasonic reflection in a certain cell. Thus, the length and width of each cell ( $d x$ and $d y$ ) of the signal matrix are $0.23 \mathrm{~mm} \times 0.23 \mathrm{~mm}$. So, the area of each cell, $d A$, was written as:

$$
d A=0.23 \times 0.23=0.0529 \mathrm{~mm}^{2} .
$$

Then the total load $F$ can be written as following:

$$
F=\sum_{j} p_{j} d A=(q)(d A) \sum_{j=1}^{n} S_{j} .
$$

Normal force $F, d A$ and $\left(\sum S_{j}\right)$ were known, then the constant $q$ could be worked out from Eq. (9). Substitute $q$ into Eq. (7), then the pressure distribution of each cell can be obtained. Figure 12 shows the pressure distribution map for the rivet/plate contact under $100 \%$ contrast ratio. From the map it discloses the pressure information, which is approximately ranged between $7.1 \mathrm{MPa}$ and 11.2 $\mathrm{MPa}$.

\section{DISCUSSION}

This work shows the processes using ultrasonic pulses to detect the anti-rotation rivet/aluminum plate interface and to 


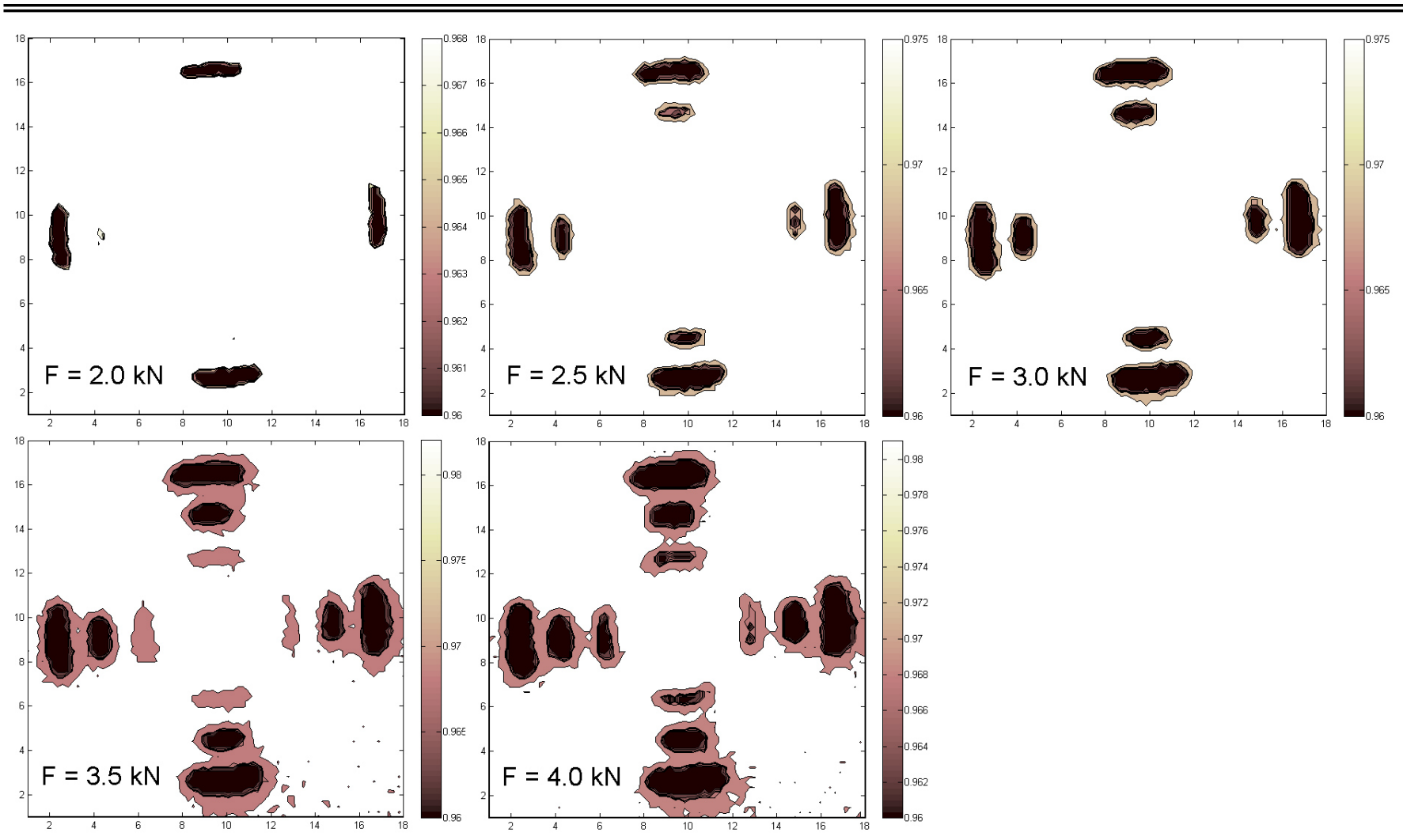

Figure 11. Maps of ultrasonic reflection coefficient for the rivet/plate contact.

identify the contact patches. The variations of contact patches for the anti-rotation rivet which has the anti-rotation design can be easily recognized. The principal purpose of measuring the contact area in this work is to obtain the pressure distribution map by further data processing. In the riveting process, the contact area between the rivets and the plate will become greater if the applied loads continuously increase. However, the contact pressures are not certainly proportional to the applied loads because the increasing area will share some loadings. Thus, knowing the pressure distribution is helpful to maintain effective riveting and to avoid the failure. This study applies an ultrasonic method to measure the contact area between an anti-rotation rivet and an aluminum plate, in which the area size can be disclosed as a reference during the riveting process. The findings provide useful scientific data for users to make the optimal and correct decision while riveting.

The 2D and 3D contact maps shown in Fig. 6 are the significant contributions in this study, especially the 3D image can indicate the contact intensity according to the amplitude of reflected signals. Therefore, ultrasonic scanning can play the role like a $3 \mathrm{D}$ camera to construct a $3 \mathrm{D}$ image, despite the real contact interface is not easily visible for inspection. Furthermore, the finite experimental data can be further processed by way of the technique of curve fitting, which makes users be able to obtain any contact area within the particular ranges of variables from the polynomial fitting equation at the limited $3 \%$ average error to the real measurement. In this process the degree of polynomial fitting equation was set to be two. If necessary, the more accuracy can be achieved if the polynomial degree was increased to be more than two.

Figure 11 shows the map of reflection coefficient and Fig. 12 shows the contact pressure map for the rivet/plate contact under five different normal loadings. Because the readings of the ultrasonic signal can reflect the degree of ease or difficulty by which the pulses pass through the rivet/plate interface, the pressure distribution can therefore be disclosed and the picture is similar to the map of reflection coefficient, which unveils the information that how many signals are reflected and received by the transducer. Theoretically the contact pressure should be symmetrically distributed. However, due to surface roughness and riveting alignment, the pressure distribution does not seem to be symmetric in the case of the smaller applied force. Figure 12 indicates the contour of pressure distribution ranged from 7.1 MPa to 11.2 MPa. It can be observed that the maximum contact pressures become less and less when the normal forces increase. It can be deduced that the contact area is increasing quickly under the greater normal force applied, which shares the pressure averagely on the contact area.

The procedure of pressure estimation was simplified by using spring contact model. The model suggests that the contact stiffness for a given contacting interfaces depends on the load applied, and hence the contact pressure between the surfaces. For a rough surface interface, it also depends on the number, size, and distribution of the asperity contacts. Therefore, there is no unique relation between stiffness and contact pressure. However, a calibration experiment ${ }^{26}$ was performed and found that over certain pressure ranges contact pressure were linearly proportional to interfacial stiffness. In a real riveting process, because of the anti-rotation designs, the antirotation rivets have to support the normal force of the contact surface. The size of the contact area is proportional to the contact load. Thus, the ultrasonic signal reading of the contact image can reflect the contact intensity between the contact interfaces. In general, the average pressure can be easily obtained from the pressure distribution equation, which is the normal load divided by the contact area. 


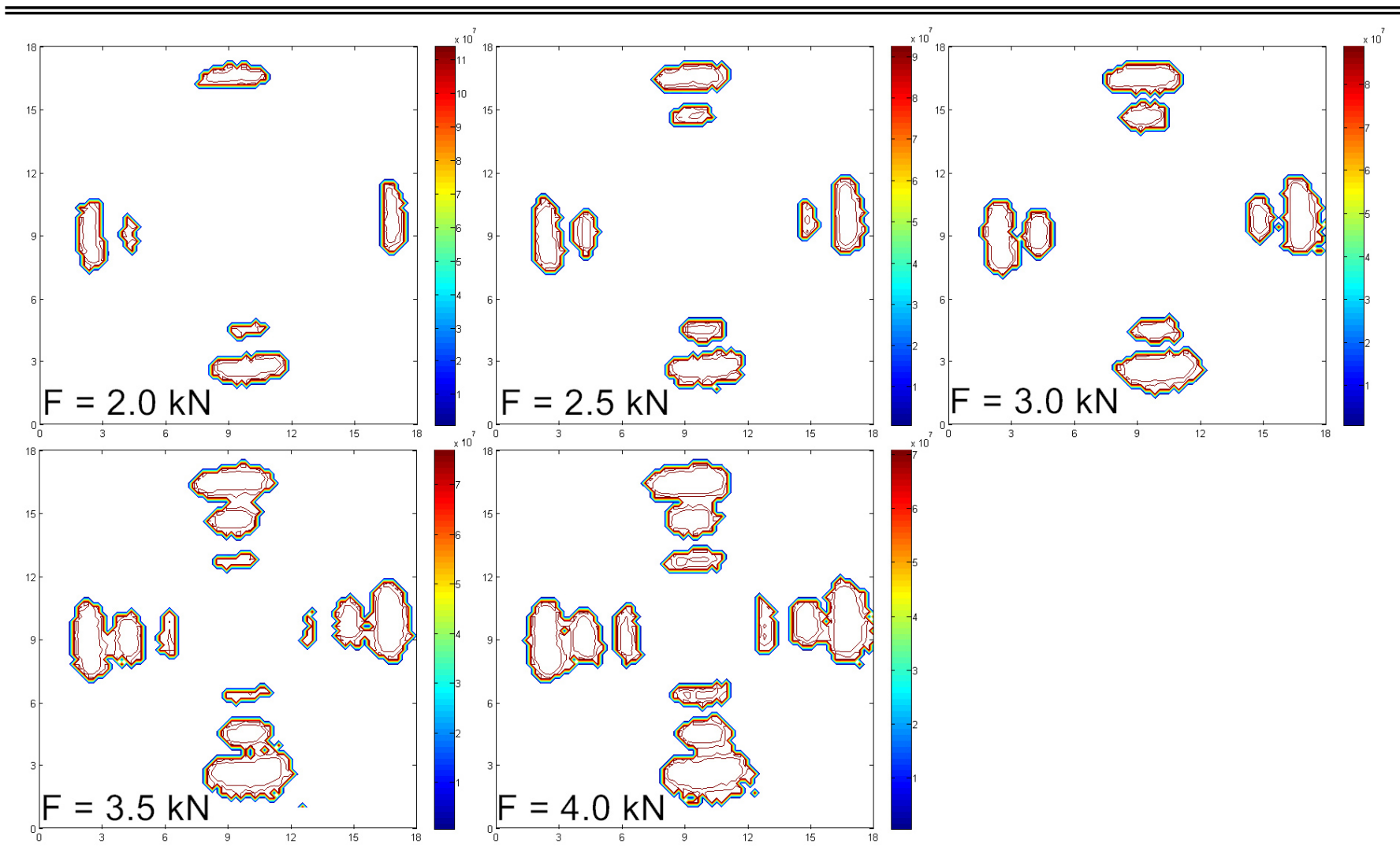

Figure 12. Map of pressure distribution of the rivet/plate contact for various loads under $100 \%$ contrast ratio.

\section{CONCLUSION}

Anti-rotation rivets are designed to prevent relative rotation between workpieces and rivets. This study investigates the contact interface between an anti-rotation rivet and an aluminum plate using ultrasonic pulse detection. The scanning images show the variation of shapes of the major separate contact patches for the rivet/plate contact under gradually increasing normal forces. It is a multi-region contact study which is difficult to analyse by mathematic contact theories. Only experimental methods can disclose the contact patches and then measure the contact area. The results of scanning tests provide useful information for the application of practical riveting, such as pressure vessel and aircraft structures.

The method used in this study is ultrasonic pulses detection. Although it is a known method, the application for measuring the contact surface of anti-rotation rivets is novel and the contact images have never been disclosed before. The ultrasonic signals are emitted and received by an ultrasonic transducer, which transmitted an acoustic wave in the form of ultrasonic energy into the rivet/plate interface being scanned and received reflected signals from the interface. Data processing allows the contact patches to be disclosed using the incident and reflected signals and then the contact areas can be worked out. Table 1 shows that the range of contact areas varies from $6.32 \mathrm{~mm}^{2}$ to $57.20 \mathrm{~mm}^{2}$ for the rivet/plate contact, depending on the normal forces and the definition of the contrast ratio.

In the meantime, the experimental data is further processed by using multivariable curve fitting technique, which makes area prediction available for any normal load ranged from 2.0 $\mathrm{kN}$ to $4.0 \mathrm{kN}$ and contrast ratio ranged from 0.1 to 1.0. The average error between prediction and real measurement is in the limited 3\% range. Table 3 shows the result comparison between the experimental data and the outcome of area prediction.

By using the application of spring contact model, the contour maps of the contact pressure are disclosed. The contours of distribution maps indicate that the pressure is not averagely distributed to the contact area. It depends on the surface asperities and roughness, which plays a significant role in the problems of contact area and contact pressure. According to the pressure contour map, it is clear to see the trend that when the contact area increases, the maximum of contact pressure decreases. In this study, the peak contact pressures range from 7.1 Mpa under the normal load 4.0 kN and 11.2 MPa under the normal force $2.0 \mathrm{kN}$.

\section{REFERENCES}

${ }^{1}$ Hoang, N. H., Hanssen, A. G., Langseth, M. and Porcaro, R. Structural behaviour of aluminium self-piercing riveted joints: An experimental and numerical investigation, International Journal of Solids and Structures, 49, 3211-3223, (2012). https://dx.doi.org/10.1016/j.ijsolstr.2012.05.039

${ }^{2}$ Han, L., Chrysanthou, A. and Young, K. W. Mechanical behaviour of self-piercing riveted multilayered joints under different specimen configurations, Materials \& Design, 28, 2024-2033, (2007). https://dx.doi.org/10.1016/j.matdes.2006.06.015

3 Han, L., Thornton, M. and Shergold, M. A comparative study between self-piercing riveting and resistance spotwelding of aluminium sheets for the automotive in- 
dustry, Materials \& Design, 31, 1457-1467, (2010). https://dx.doi.org/10.1016/j.matdes.2009.08.031

4 Xiaocong, H., Pearson, I. and Young, K. Self-pierce riveting for sheet materials: state of the art, Journal of Materials Processing Technology, 199, 27-36, (2008). https://dx.doi.org/10.1016/j.jmatprotec.2007.10.071

5 Hoang, N. H., Porcaro, R., Langseth, M. and Hanssen, A. G. Self-piercing riveting connections using aluminium rivets, International Journal of Solids and Structures, 47, 427-439, (2010). https://dx.doi.org/10.1016/j.ijsolstr.2009.10.009

6 Abe, Y., Kato, T. and Mori, K. Aluminum alloy self-pierce riveting for joining of aluminium alloy sheets, Key Engineering Materials, 410, 79-86, (2009). https://dx.doi.org/10.4028/www.scientific.net/KEM.410411.79

7 Pilkey, W. D. and Pilkey, D. F. Peterson's Stress Concentration Factors, third ed. John Wiley \& Sons, New York, (2008).

8 Abidin, I. Z., Mandache, C., Tian, G. Y. and Morozov, M. Pulsed eddy current testing with variable duty cycle on rivet joints, NDT\&E International, 42, 599-605, (2009). https://dx.doi.org/10.1016/j.ndteint.2009.04.001

9 He, Y., Luo, F., Pan, M., Weng, F., Hu, X., Gao, J. and Liu, B. Pulsed eddy current technique for defect detection in aircraft riveted structures, NDT\&E International, 43, 176-181, (2010). https://dx.doi.org/10.1016/j.ndteint.2009.10.010

10 Diraison, Y. L., Joubert, P. and Placko, D. Characterization of subsurface defects in aeronautical riveted lap-joints using multi-frequency eddy current imaging, NDT\&E International, 42, 133-140, (2009). https://dx.doi.org/10.1016/j.ndteint.2008.10.005

11 Liu, Z., Forsyth, D. S., Marincak, A. and Vesley, P. Automated rivet detection in the EOL image for aircraft lap joints inspection, NDT\&E International, 39, 441-448, (2006). https://dx.doi.org/10.1016/j.ndteint.2006.01.002

12 Yan, W., Xie, Z., Yu, C., Song, L. and He, H. Experimental investigation and design method for the shear strength of self-piercing rivet connections in thin-walled steel structures, Journal of Constructional Steel Research, 133, 231240, (2017). https://dx.doi.org/10.1016/j.jcsr.2017.02.022

13 Guy, A. Rivet with improved contact surface, WIPO patent, publication,No. 20130011217, (2013).

14 Yao, C. W., Zhou, L. Z. and Chien, Y. X. Measurement of the Contact Area of a Dovetail Milling Cutter Using an Ultrasonic Method, Measurement, 46, 3211-3219, (2013). https://dx.doi.org/10.1016/j.measurement.2013.04.060

15 Lewis, R., Marshall, M. B. and Dwyer-Joyce, R. S. Measurement of Interface Pressure in Interference Fits, Proceedings of the Institution of Mechanical Engineers, Part C: Journal of Mechanical Engineering Science, 219, 127139, (2005). https://dx.doi.org/10.1243/095440605X8432
16 Marshall, M. B., Lewis, R. and Dwyer-Joyce, R. S. Characterisation of Contact Pressure Distribution in Bolted Joints, Strain, 42, 31-43, (2006). https://dx.doi.org/10.1111/j.1475-1305.2006.00247.x

17 Tattersall, H. The ultrasonic pulse-echo technique as applied to adhesion testing. Journal of Physics D: Applied Physics, 6, 819-832, (1973). https://dx.doi.org/10.1088/0022-3727/6/7/305

18 Nagy, P. B. Ultrasonic classification of imperfect interfaces, Journal of Nondestructive Evaluation, 11, 127-139, (1992). https://dx.doi.org/10.1007/BF00566404

19 Drinkwater, B. W., Dwyer-Joyce, R. S. and Cawley, P. A study of the interaction between ultrasound and a partially contacting solid-solid interface, Proceedings of the Royal Society, 452, 2613-2628, (1996). https://dx.doi.org/10.1098/rspa.1996.0139

20 Baltazar, A., Rokhlin, S. and Pecorari, C. On the relationship between ultrasonic and micromechanical properties of contacting rough surfaces, Journal of the Mechanics and Physics of Solids, 50, 1397-1416, (2002). https://dx.doi.org/10.1016/S0022-5096(01)00119-3

21 Dwyer-Joyce, R. S., Drinkwater, B. W. and Quinn, A. M. The Use of Ultrasound in the Investigation of Rough Surface Interfaces, Journal of Tribology, 123, 8-16, (2001). https://dx.doi.org/10.1115/1.1330740

22 Gonzalez-Valadez, M., Baltazar, A. and Dwyer-Joyce, R. S. Study of interfacial stiffness ratio of a rough surface in contact using a spring model, Wear, 268, 373-379, (2010). https://dx.doi.org/10.1016/j.wear.2009.08.022

23 Thomas, T. R. and Sayles, R. S. Random-process approach to the prediction of joint stiffness, Journal of Engineering for Industry, 99B, 250-256, (1977). https://dx.doi.org/10.1115/1.3439147

24 Marshall, M. B., Lewis, R. Dwyer-Joyce, R. S., Olofsson, U. and Bjorklund, S. Experimental Characterisation of Wheel-Rail Contact Patch Evolution, Journal of Tribology, 128, 493-504, (2006). https://dx.doi.org/10.1115/1.2197523

25 Yao, C. W. and Chien, Y. X. A Diagnosis Method of Wear and Tool Life for an Endmill by Ultrasonic Detection, Journal of Manufacturing Systems, 33, 129-138, (2014). https://dx.doi.org/10.1016/j.jmsy.2013.05.003

26 Hodgson, K., Dywer-Joyce, R. S. and Drinkwater, B. W. Ultrasound as an Experimental Tool for Investigating Engineering Contacts, Proceedings of the 9th Nordic Symposium on Tribology, 2, 377-386, (2000). 